\title{
ANALISIS KESTABILAN TITIK TETAP PADA MODEL MATEMATIKA PENYEBARAN HIV/AIDS
}

\author{
Moch. Fahmi Lamusu ${ }^{1}$, Dewinta Mamula ${ }^{2 *}$, Fitriyani Muhsana ${ }^{3}$ \\ 1,2,3 Jurusan Matematika, Universitas Negeri Gorontalo, Bone Bolango 96119, Indonesia \\ *Penulis Korespondensi. Email: dewintamamula@gmail.com
}

\begin{abstract}
Abstrak
Artikel ini membahas tentang virus yang merusak sistem kekebalan tubuh, dengan menginfeksi dan menghancurkan sel CD4, yaitu virus HIV (human immunodefiency virus). Infeksi HIV yang tidak segera ditangani akan berkembang menjadi kondisi yang serius yang disebut AIDS (Acquired Immune Defiency Syndrome). Tujuan penulisan artikel ini adalah Mengetahui model epidemik SIA pada penularan penyakit HIV/AIDS, Mengetahui titik kesetimbangan dan melakukan analisis kestabilan dan Mengetahui penularan dan pencegahan penyakit HIV/AIDS. Hasil pembahasan menunjukkan jika kedua kota dalam kondisi endemik HIV/AIDS dibuktikan dengan nilai $R_{0}>1$. Jika $R_{0}<1$ maka hanya terdapat satu titik kesetimbangan bebas penyakit yang stabil. $R_{0}>1$ maka terdapat dua titik kesetimbangan, titik kesetimbangan bebas penyakit yang tidak stabil, dan titik kesetimbangan endemi yang stabil.
\end{abstract}

Kata Kunci: HIV/AIDS; Model Matematika; Titik Tetap; Analisis Kestabilan

\section{Pendahuluan}

HIV (human immunodefiency virus) adalah virus yang merusak sistem kekebalan tubuh, dengan menginfeksi dan menghancurkan sel CD4. Semakin banyak sel CD4 yang dihancurkan, kekebalan tubuh akan semakin lemah, sehingga rentan riserangi berbagai penyakit. Infeksi HIV yang tidak segera ditangani akan berkembang menjadi kondisi yang serius yang disebut AIDS (Acquired Immune Defiency Syndrome). AIDS adalah stadium akhir dari infeksi virus HIV. Pada tahap ini, kemampuan tubuh untuk melawan infeksi sudah hilang sepenuhnya. Sampai saat ini belum ada obat untuk menangani HIV dan AIDS. Akan tetapi, ada obat untuk memperlambat perkembangan penyakit tersebut dan dapat meningkatkan harapan hidup penderita.

Model matematika seringkali digunakan untuk menjelaskan fenomena dalam bidang biologi, seperti penyebaran penyakit menular. Fenomena tersebut dimodelkan oleh persamaan diferensial dengan representasi proses waktu kontinu. [1] melakukan penelitian analisa kestabilan penyebaran HIV/AIDS dengan edukasi kesehatan melalui perluasan model SI (Susceptible-Infected), dampak edukasi kesehatan pada penyebaran penyakit HIV/AIDS dikaji dengan analisis sensitivitas angka reproduksi efektif terhadap semua parameter yang mendorong dinamika penyakit. [2] membahas tentang model SIA transmisi HIV di Ghana. Berdasarkan referensi dari penelitian yang telah dilakukan sebelumnya, dalam penelitian ini dikaji model matematika dinamika transmisi atau penularan HIV/AIDS.

Model matematika epidemic yang akan dibahas dalam penelitian ini adalah model epidemic penularan HIV/AIDS yang dimodelkan dalam bentuk SIA. Model epidemic pada penularan HIV/AIDS ini, populasi manusia pada waktu t tetap terbagi dalam 3 populasi yaitu S, I, dan A. individu-individu yang termasuk dalam kelompok Susceptible (S), menyatakan kelompok awal populasi yang rentan terkena penyakit. Infective (I), menyatakan kelompok populasi yang terinfeksi penyakit. AIDS (A) yaitu kelompok populasi yang sudah terkena penyakit.

Tujuan penelitian ini yaitu untuk mengetahui titik kesetimbangan, melakukan analisis kestabilannya, menentukan bilangan reproduksi dasar, Mengetahui model epidemic SIA pada penularan penyakit HIV/AIDS, dan Mengetahui penularan dan pencegahan penyakit HIV/AIDS.

\section{Metode Penelitian}

Metode yang digunakan pada penelitian ini adalah kajian pustaka dengan tahap-tahap: (1) penentuan masalah, (2) perumusan masalah, (3) studi pustaka, (4) analisis dan pemecahan masalah, (5) penarikan 
kesimpulan. Pemilihan dan perumusan masalah diperlukan untuk membatasi permasalahan sehingga diperoleh bahan kajian yang jelas. Sehingga akan lebih mudah untuk menentukan langkah dalam memecahkan masalah tersebut.

Tahap studi pustaka dilakukan dengan mengkaji sumber-sumber pustaka sehingga dieroleh gambaran umum dan populasinya, model matematika, model epidemic SIA, sistem persamaan diferensial, nilai eigen dan fektor eigen, simulasi model dengan software matematica. Dalam pembahasan ini dilakukan beberapa langkah pokok yaitu. (1) Membangun model matematika pada penyebaran penyakit HIV/AIDS, (2) mencari titik kesetimbangan dari model matematika, (3) menentukan bilangan reproduksi dasar $\left(R_{0}\right),(4)$ menganalisis kestabilan titik kesetimbangan, (5) menginterpretasikan solusi model matematika.

\section{Pembahasan}

Model epidemic pada penularan HIV/AIDS ini, populasi manusia pada waktu t tetap terbagi dalam 3 populasi yaitu S, I, dan A. individu-individu yang termasuk dalam kelompok Susceptible (S), menyatakan kelompok awal populasi yang rentan terkena penyakit. Infective (I), menyatakan kelompok populasi yang terinfeksi penyakit. AIDS (A) yaitu kelompok populasi yang sudah terkena penyakit. Secara skematis diberikan pada Gambar 1.

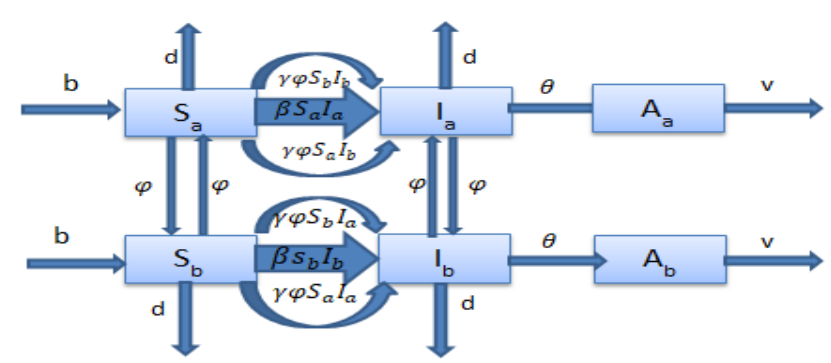

Gambar 1. Skema penularan penyakit HIV/AIDS

Berdasarkan skema pada Gambar 1, diperoleh model matematika dalam bentuk sistem persamaan diferensial sebagai berikut:

$$
\begin{aligned}
& \frac{d s_{a}}{d t}=\mathrm{b}+\varphi s_{b}-\varphi s_{a}-d s_{a}-\beta s_{a} I_{a}-\gamma \varphi s_{b} I_{b}-\gamma \varphi s_{a} I_{b} \\
& \frac{d I_{a}}{d t}=\beta s_{a} I_{a}+\varphi I_{b}-\varphi I_{a}+\gamma \varphi s_{b} I_{b}+\gamma \varphi s_{a} I_{b}-d I_{a}-\theta I a \\
& \frac{d A_{a}}{d t}=\theta I_{a}-v A_{a} \\
& \frac{d s_{b}}{d t}=\mathrm{b}-d s_{b}+\varphi s_{a}-\varphi s_{b}-\beta s_{b} I_{b}-\gamma \varphi s_{a} I_{a}-\gamma \varphi s_{b} I_{a} \\
& \frac{d I_{b}}{d t}=\beta s_{b} I_{b}+\varphi I_{a}-\varphi I_{b}+\gamma \varphi s_{a} I_{a}+\gamma \varphi s_{b} I_{a}-d I_{b}-\theta I_{b} \\
& \frac{d A_{a}}{d t}=\theta I_{b}-v A_{b}
\end{aligned}
$$

dengan $S_{i}, I_{i}, A_{i}$ mewakili banyaknya populasi Susceptible, Infective, dan AIDS. Kedua kota diasumsikan identic, sehingga parameter yang digunakan kedua kota sama. Parameter-parameter yang digunakan yaitu:

$$
\begin{aligned}
& \mathrm{b}=\text { laju kelahiran } \\
& \mathrm{d}=\text { Rata rata kematian alami } \\
& \beta=\text { Rata rata penularan } \\
& \varphi=\text { rata rata perpindahan penduduk }
\end{aligned}
$$


$\gamma=$ rata rata penularan antar wilayah

$\theta=$ rata rata perubahan dari HIV menjadi AIDS

$\mathrm{v}=$ rata rata kematian akibat HIV/AIDS

$\mathrm{Sa}=$ populasi dari individu-individu rentan di KOTA A

Ia = populasi dari individu-individu terinfeksi HIV di KOTA A

$\mathrm{Aa}=$ populasi individu yang telah mencapai fase AIDS di KOTA A

$\mathrm{Sb}=$ populasi dari individu-individu rentan di KOTA B

$\mathrm{Ib}=$ populasi dari individu-individu terinfeksi HIV di KOTA B

$\mathrm{Ab}=$ populasi individu yang telah mencapai fase AIDS di KOTA B

\subsection{Titik Tetap Tanpa Penyakit}

Dengan membuat : $\frac{d S_{a}}{d t}=\frac{d I_{a}}{d t}=\frac{d A_{a}}{d t}=\frac{d S_{b}}{d t}=\frac{d I_{b}}{d t}=\frac{d A_{b}}{d t}=0$, maka:

$$
\begin{aligned}
\frac{d S_{a}}{d t} & =b+\varphi S_{b}-\varphi S_{a}-d S_{a}-\beta S_{a} I_{a}-\gamma \varphi S_{b} I_{b}-\gamma \varphi S_{a} I_{b}=0 \\
& \Rightarrow b+\varphi S_{b}-\varphi S_{a}-d S_{a}=0 \\
& \Rightarrow b+\varphi S_{b}-(\varphi+d) S_{a}=0 \\
& \Rightarrow S_{a}=\frac{b+\varphi S_{a}}{\varphi+d} \\
\frac{d S_{b}}{d t} & =b-d S_{b}+\varphi S_{a}-\varphi S_{b}-\beta S_{b} I_{b}-\gamma \varphi S_{a} I_{a}-\gamma \varphi S_{b} I_{b}=0 \\
& \Rightarrow b-d S_{b}+\varphi S_{a}-\varphi S_{b}=0 \\
& \Rightarrow b-(d+\varphi) S_{a}-\varphi S_{b}=0 \\
& \Rightarrow b-d S_{b}+\varphi S_{a}-\varphi\left(\frac{b+\varphi S_{a}}{\varphi+d}\right)=0 \\
& \Rightarrow(\varphi+d) b-(\varphi+d)^{2} S_{b}+\varphi\left(b+\varphi S_{b}\right)=0 \\
& \Rightarrow \varphi b+d b-(\varphi+d)^{2} S_{b}+\varphi b+\varphi^{2} S_{b}=0 \\
& \Rightarrow \varphi b+d b+\varphi b+\left[\varphi^{2}-(\varphi+d)^{2}\right] S_{b}=0 \\
& \Rightarrow 2 \varphi b+d b+\left[\varphi^{2}-\varphi^{2}-2 \varphi d-d^{2}\right] S_{b}=0 \\
& \Rightarrow\left(2 \varphi d+d^{2}\right) S_{b}=2 \varphi b+d b \\
& \Rightarrow S_{b}=\frac{b}{d} \\
& \Rightarrow S_{b}=\frac{2 \varphi b+d b}{2 \varphi d+d^{2}} \\
& \Rightarrow b(2 \varphi+d) \\
&
\end{aligned}
$$

Dari persamaan (1), yaitu :

$$
S_{a}=\frac{b+\varphi S_{a}}{\varphi+d} \quad \text { Substitusi nilai } S_{b}=\frac{b}{d}
$$




$$
\begin{aligned}
& S_{a}=\frac{b+\varphi \frac{b}{d}}{\varphi+d} \\
& S_{a}=\frac{\frac{b d+\varphi b}{d}}{\varphi+d} \\
& S_{a}=\frac{b d+\varphi b}{d(\varphi+d)} \\
& S_{a}=\frac{b(\varphi+d)}{d(\varphi+d)} \\
& S_{a}=\frac{b}{d}
\end{aligned}
$$

Didapat titik tetap tanpa penyakit

$$
P_{0}=\left(S_{a}, I_{a}, A_{a}, S_{b}, I_{b}, A_{b}\right)=\left(\frac{b}{d}, 0,0, \frac{b}{d}, 0,0\right)
$$

\subsection{Mencari Bilangan Reproduksi Dasar (RO)}

Dengan mengambil sistem persamaan yang memuat populasi teinfeksi (I) dan populasi AIDS (A) pada kedua kota

$\frac{d I_{a}}{d t}=\beta S_{a} I_{a}+\gamma \varphi S_{b} I_{b}+\gamma \varphi S_{a} I_{b}+\varphi I_{b}-\varphi I_{a}-d I_{a}-\theta I_{a}$

$\frac{d A_{a}}{d t}=\theta I_{a}-v A_{a}$

$\frac{d I_{b}}{d t}=\beta S_{b} I_{b}+\gamma \varphi S_{a} I_{a}+\gamma \varphi S_{b} I_{a}+\varphi I_{a}-\varphi I_{b}-d I_{b}-\theta I_{b}$

$\frac{d A_{b}}{d t}=\theta I_{b}-v A_{b}$

Jumlahkan persamaan (1) dan (3), (2) dan (4):

$\frac{d I_{a}}{d t}+\frac{d I_{b}}{d t}=\beta S_{a} I_{a}+\beta S_{b} I_{b}+\gamma \varphi S_{b} I_{b}+\gamma \varphi S_{a} I_{a}+\gamma \varphi S_{a} I_{b}+\gamma \varphi S_{b} I_{a}-d I_{a}-d I_{b}-\theta I_{a}-\theta I_{b}$

$\frac{d A_{a}}{d t}+\frac{d A_{b}}{d t}=\theta I_{a}+\theta I_{b}-v A_{a}-v A_{b}$

Maka berdasarkan persamaan diatas diperoleh matriks $\mathrm{F}$ dan $\mathrm{V}$, sebagai berikut :

$F=\left[\begin{array}{c}\beta S_{a} I_{a}+\beta S_{b} I_{b}+\gamma \varphi S_{b} I_{b}+\gamma \varphi S_{a} I_{a}+\gamma \varphi S_{a} I_{b}+\gamma \varphi S_{b} I_{a} \\ \theta I_{a}+\theta I_{b}\end{array}\right]$

$V=\left[\begin{array}{c}(d+\theta) I_{a}+(d+\theta) I_{b} \\ v A_{a}+v A_{b}\end{array}\right]$

Matriks jacobian dari matriks diatas adalah sebagai berikut :

$F=j(F)=\left[\begin{array}{cc}\beta S_{a}+\gamma \varphi S_{a}+\gamma \varphi S_{b} & 0 \\ \theta & 0\end{array}\right], \quad V=j(V)=\left[\begin{array}{cc}d+\theta & 0 \\ 0 & v\end{array}\right]$

Substitusi titik tetap tanpa penyakit kepersamaan diatas :

$F=\left[\begin{array}{cc}\beta \frac{b}{d}+\gamma \varphi \frac{b}{d}+\gamma \varphi \frac{b}{d} & 0 \\ \theta & 0\end{array}\right]$ 
$F=\left[\begin{array}{cc}\frac{\beta b+2 \gamma \varphi b}{d} & 0 \\ \theta & 0\end{array}\right]$

$V=\left[\begin{array}{cc}d+\theta & 0 \\ 0 & v\end{array}\right]$

Menentukan matriks next generation (K), dimana $K=F \cdot V^{-1}$ karena,

$V=\left[\begin{array}{cc}d+\theta & 0 \\ 0 & v\end{array}\right], \quad V=\left[\begin{array}{cc}\frac{1}{d+\theta} & 0 \\ 0 & \frac{1}{v}\end{array}\right]$

Maka didapat $\mathrm{K}$ :

$K=\left[\begin{array}{cc}\frac{\beta b+2 \gamma \varphi b}{d} & 0 \\ \theta & 0\end{array}\right] \cdot\left[\begin{array}{cc}\frac{1}{d+\theta} & 0 \\ 0 & \frac{1}{v}\end{array}\right]$

$K=\left[\begin{array}{cc}\frac{\beta b+2 \gamma \varphi b}{d(d+\theta)} & 0 \\ \frac{\theta}{d+\theta} & 0\end{array}\right]$

Akan ditentukan $\mathrm{R} 0$ dengan mencari nilai eigen positif terbesar dari matriks $\mathrm{K}$

$|K-\lambda I|=0$

$\left\|\left[\begin{array}{cc}\frac{\beta b+2 \gamma \varphi b}{d(d+\theta)}-\lambda & 0 \\ \frac{\theta}{d+\theta} & -\lambda\end{array}\right]\right\|=0$

$\left(\frac{\beta b+2 \gamma \varphi b}{d(d+\theta)}-\lambda\right)(-\lambda)=0$

$\lambda_{1}=0, \quad \lambda_{2}=\frac{\beta b+2 \gamma \varphi b}{d(d+\theta)}$

Dapat ditentukan $\mathrm{R} 0$ adalah nilai eigen positif terbesar :

$R_{0}=\frac{\beta b+2 \gamma \varphi b}{d(d+\theta)}$

Menentukan matriks jacobian untuk titik tetap tanpa penyakit

$$
J=\left[\begin{array}{cccccc}
A & B & 0 & C & D & 0 \\
0 & E & 0 & 0 & F & 0 \\
0 & G & H & 0 & 0 & 0 \\
C & D & 0 & A & B & 0 \\
0 & F & 0 & 0 & E & 0 \\
0 & 0 & 0 & 0 & G & H
\end{array}\right], \text { dimana }
$$

$A=-\varphi-d$

$B=-\frac{b \beta}{d}$

$C=\varphi$

$D=\frac{2 \gamma \varphi b}{d}$ 
$E=\frac{b \beta-\varphi d-d^{2}-\theta d}{d}$

$F=\frac{2 \gamma \varphi b+d \varphi}{d}$

$G=\theta$

$H=-v$

\subsection{Mencari Nilai Eigen Matriks Jacobian untuk Titik Tetap Tanpa Penyakit}

Menentukan determinan matriks J

$$
\begin{aligned}
& |J|=\left[\begin{array}{cccccc}
A & B & 0 & C & D & 0 \\
0 & E & 0 & 0 & F & 0 \\
0 & G & H & 0 & 0 & 0 \\
C & D & 0 & A & B & 0 \\
0 & F & 0 & 0 & E & 0 \\
0 & 0 & 0 & 0 & G & H
\end{array}\right] \longrightarrow \begin{array}{l}
-\frac{D}{E} b_{5}+b_{1} \\
-\frac{F}{E} b_{5}+b_{2}
\end{array} \\
& {[J]=\left[\begin{array}{cccccc}
A & \frac{B E-D F}{E} & 0 & C & 0 & 0 \\
0 & \frac{E^{2}-F^{2}}{E} & 0 & 0 & 0 & 0 \\
0 & G & H & 0 & 0 & 0 \\
C & D & 0 & A & B & 0 \\
0 & F & 0 & 0 & E & 0 \\
0 & 0 & 0 & 0 & G & H
\end{array}\right] \longrightarrow-\frac{B}{E} b_{5}+b_{4}} \\
& {[J]=\left[\begin{array}{cccccc}
A & \frac{B E-D F}{E} & 0 & C & 0 & 0 \\
0 & \frac{E^{2}-F^{2}}{E} & 0 & 0 & 0 & 0 \\
0 & G & H & 0 & 0 & 0 \\
C & \frac{D E-B F}{E} & 0 & A & 0 & 0 \\
0 & F & 0 & 0 & E & 0 \\
0 & 0 & 0 & 0 & G & H
\end{array}\right] \longrightarrow c \frac{D F-B E}{E^{2}-F^{2}} b_{2}+b_{1}} \\
& {[J]=\left[\begin{array}{cccccc}
A & 0 & 0 & C & 0 & 0 \\
0 & \frac{E^{2}-F^{2}}{E} & 0 & 0 & 0 & 0 \\
0 & G & H & 0 & 0 & 0 \\
C & \frac{D E-B F}{E} & 0 & A & 0 & 0 \\
0 & F & 0 & 0 & E & 0 \\
0 & 0 & 0 & 0 & G & H
\end{array}\right] \longrightarrow \frac{B F-D E}{E^{2}+F^{2}} b_{2}+b_{4}} \\
& -\frac{C}{A} b_{4}+b_{1}
\end{aligned}
$$




$$
\begin{aligned}
& {[J]=\left[\begin{array}{cccccc}
A & 0 & 0 & C & 0 & 0 \\
0 & \frac{E^{2}-F^{2}}{E} & 0 & 0 & 0 & 0 \\
0 & G & H & 0 & 0 & 0 \\
C & 0 & 0 & A & 0 & 0 \\
0 & F & 0 & 0 & E & 0 \\
0 & 0 & 0 & 0 & G & H
\end{array}\right] \longrightarrow} \\
& {[J]=\left[\begin{array}{cccccc}
\frac{A^{2}-C^{2}}{A} & 0 & 0 & 0 & 0 & 0 \\
0 & \frac{E^{2}-F^{2}}{E} & 0 & 0 & 0 & 0 \\
0 & G & H & 0 & 0 & 0 \\
C & 0 & 0 & A & 0 & 0 \\
0 & 0 & 0 & 0 & E & 0 \\
0 & 0 & 0 & 0 & G & H
\end{array}\right]}
\end{aligned}
$$

Didapat $[\mathrm{J}]$ adalah perkalian elemen diagonal matriks diatas :

$[J]=\left(\frac{A^{2}-C^{2}}{A}\right) \cdot\left(\frac{E^{2}-F^{2}}{E}\right) \cdot H \cdot A \cdot E \cdot H$

$[J]=\left(A^{2}-C^{2}\right)\left(E^{2}-F^{2}\right), H^{2}$

Untuk mencari $|J-\lambda I|$, kita hanya perlu mengganti $\left\{J_{i j} \mid i=j\right\}$ pada matriks awal $\mathrm{J}$, dengan $\left\{J_{i j} \mid i=j\right\}$. Perlu diingat bahwa $J_{i j}$ untuk $\mathrm{i}=\mathrm{j}$ adalah elemen dragonal matriks $\mathrm{J}$. Yaitu : A, E, H, A, E, H

Maka didapat :

$$
\begin{aligned}
&|J-\lambda I|=\left[(A-\lambda)^{2}-C^{2}\right]\left[(E-\lambda)^{2}-F^{2}\right]\left[(H-\lambda)^{2}\right]=0 \\
& \Rightarrow(A-\lambda)^{2}-C^{2}=0 \\
& \lambda^{2}-2 A \lambda+A^{2}-C^{2}=0 \\
& {[\lambda-(A+C)][\lambda-(A-C)]=0 } \\
& \lambda_{1}=A+C \\
& \lambda_{2}=A-C \\
& \Rightarrow(E-\lambda)^{2}-F^{2}=0 \\
& \lambda^{2}-2 E \lambda+E^{2}-F^{2}=0 \\
& {[\lambda-(E+F)][\lambda-(E-F)]=0 } \\
& \lambda_{3}=E+F \\
& \lambda_{4}=E-F \\
& \Rightarrow(H-\lambda)^{2}=0 \\
&(H-\lambda) .(H-\lambda)=0 \\
& \lambda_{5}=H \\
& \lambda_{6}=H
\end{aligned}
$$




$$
\begin{aligned}
& \text { 3.4. Analisis kestabilan } \\
& \lambda_{1}=A+C \\
& =(-\varphi-d)+\varphi \\
& =-d \\
& \lambda_{2}=A-C \\
& =(-\varphi-d)-(\varphi) \\
& =-2 \varphi-d \\
& \lambda_{3}=E+F \\
& =\frac{b \beta-\varphi d-d^{2}-\theta d}{d}+\frac{2 \gamma \varphi b+d \varphi}{d} \\
& =\frac{b \beta-\varphi d-d^{2}-\theta d+2 \gamma \varphi b+d \varphi}{d} \\
& =\frac{b \beta-d^{2}-\theta d+2 \gamma \varphi b}{d}
\end{aligned}
$$

$\lambda_{4}=E-F$

$$
\begin{aligned}
& =\frac{b \beta-\varphi d-d^{2}-\theta d}{d}-\frac{2 \gamma \varphi b+d \varphi}{d} \\
& =\frac{b \beta-\varphi d-d^{2}-\theta d-2 \gamma \varphi b+d \varphi}{d}
\end{aligned}
$$

$\lambda_{5}=\lambda_{6}=H$

$$
=-v
$$

$\Rightarrow$ untuk $\lambda_{3}$,

$$
\begin{aligned}
\lambda_{3}= & \frac{b \beta-d^{2}-\theta d+2 \gamma \varphi b}{d}<0 \\
& \frac{b \beta+2 \gamma \varphi b-d(d+\theta)}{d}<0 \\
& \frac{b \beta+2 \gamma \varphi b}{d}-(d+\theta)<0 \\
& \frac{b \beta+2 \gamma \varphi b}{d}<(d+\theta) \\
& \frac{b \beta+2 \gamma \varphi b}{d(d+\theta)}<1
\end{aligned}
$$

Maka $\lambda_{3}<0$ jika $R_{0}<1$

\subsection{Simulasi Numerik}

Simulasi dilakukan dengan menggunakan software Matematica dan dengan memberikan nilai-nilai untuk masing-masing parameter sesuai dengan kondisi $R_{0}$ dalam teorema-teorema yang telah diberikan diatas. Simulasi ini diberikan untuk memberikan gambaran geometris dari teorema eksistensi dan kestabilan dari titik tetap model SIA ini. Dalam model ini akan dianalisis dinamika penularan penyakit HIV/AIDS dengan menggunakan nilai parameter pada Tabel 1. Dinamika populasi dapat dilihat pada Gambar 2. 
Tabel 1. Nilai-nilai parameter simulasi

\begin{tabular}{clc}
\hline Simbol & Keterangan & Nilai \\
\hline B & Laju Kelahiran & 28.56 \\
D & Rata-rata kematian alami & 0.00021 \\
$\beta$ & Rata-rata penularan & 0.000113 \\
$\gamma$ & Rata-rata penularan antar wilayah & 0.000113 \\
$\theta$ & Rata-rata perubahan dari HIV menjadi AIDS & 0.435 \\
$\mathrm{~V}$ & Rata-rata kematian akibat HIV/AIDS & 0.253 \\
$\varphi$ & Rata-rata perpindahan penduduk & 0.002 \\
\hline
\end{tabular}
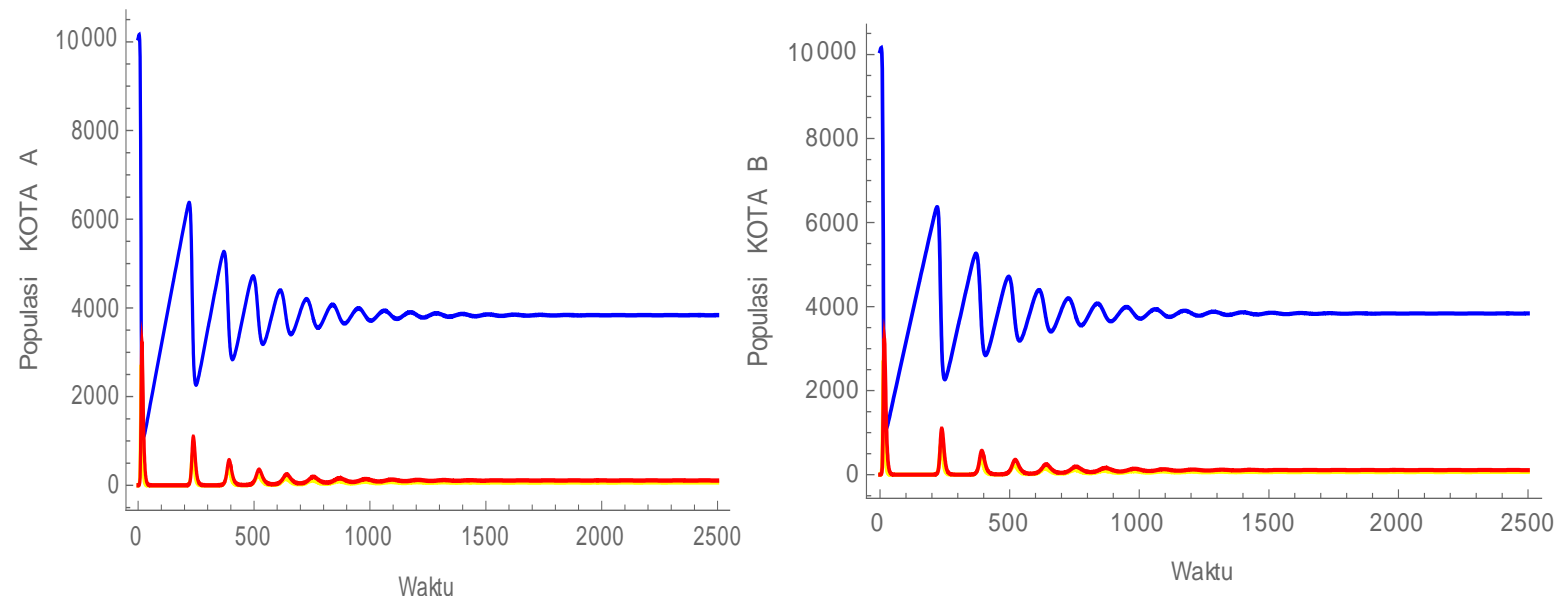

Gambar 2. Dinamika populasi kota A dan Kota B

\section{Kesimpulan}

Berdasarkan hasil analisis penelitian ini diperoleh hasil kesimpulan yaitu: (1) Diperoleh titik kesetimbangan, yaitu titik kesetimbangan bebas penyakit $P_{0}$ dan titik kesetimbangan endemik $P_{*}$, (2) Bilangan reproduksi dasar $R_{0}$ menentukan eksistensi dan jenis kestabilan titik kesetimbangan. Jika $R_{0}<1$ maka hanya terdapat satu titik kesetimbangan bebas penyakit yang stabil. $R_{0}>0$ maka terdapat dua titik kesetimbangan, titik kesetimbangan bebas penyakit yang tidak stabil, dan titik kesetimbangan endemi yang stabil, (3) Sampai saat ini belum ada obat ataupunvaksi untuk mencegah dan menyembuhkan infeksi HIV/AIDS. Tetapi, pencegahan dapat dilakukan dengan beberapa cara, antara lain: menggunakan kondom setiap kali berhungan seks dan menghindari penggunaan jarum bekas.

\section{Referensi}

[1] Marsudi, M. dan R. B. E. Wibowo. 2013. Model Matematika Penyebaran HIV/AIDS dengan Edukasi Kesehatan. Natural B. Volume 2(1).

[2] Eduafo, S. I. K. Adu, F. T. Oduro, dan I. O. Darko. 2015. An SIA Model of HIV Transmission in Ghana. International Mathematical Forum. Volume 10(2): 95-104.1.

[3] Ault, J.C and Ayres, Frank. Persamaan Diferensial dalam satuan SI Metric.Jakarta: Erlangga.

[4] Bayer R. Stigma and the ethics of public health: not can we but should we. Social Science \& Medicine. 2008; 67(3): 463-72.

[5] Braun, M. Differential Equaations and Their Application. New York:Springer-Verlag.

[6] Diekman O, Heesterbeek JAP. Mathematical Epidemiology of Infection Diseases.USA:John Wiley and Son, Ltd.

[7] Gireig. F. Koopman, C. 2003 Multi Level Analysis of Women's Empowermant and HIV prevention: Quantitative Survey Result from Preliminary Study in Bostwana. J. AIDS behavior, 7: 195-208.

[8] Hia ME, Balatif O, Ferjouchia H, Labriji EH, Rachik M. Modelling the spread of HIV/AIDS in Morocco. International Journal of Computer Sciences Issues Morocco. 2019;9(6). 
[9] Infodatin. 2016. Situasi Penyakit HIV AIDS di Indonesia. Pusat Data dan Informasi Kementrian Kesehatan RI: Jakarta Selatan.

[10] Jiang, D., C. Ji, N. Shi, dan J. Yu. 2010. The Long Time Behavior of DI SIR Epidemic Model with Stochastic Perturbation. Journal of Mathematical Analysis and Applications. Volume 372: 162-180.

[11] Murray JD. Mathematical Biology Third Edition. New York: Berlin Heidelberg; 2002.

[12] Sutimin, Imamudin. Model Dinamika Penularan Human Immunodificiency Virus (HIV). Jurnal Sains dan Matematika Universitas Diponegoro. 2009;17(1).

[13] Syamsuddin, Toaha. Pemodelan Matematika Dalam Dinamika Populasi.Makassar:Dua Satu Press.

[14] Wan, H. dan J. Cui. 2007. An SEIS Epidemic Model with Transport-Related Infection. Journal of Theoretical Biology. Volume 247(3): 507-724. 